\title{
CAMPYLOBACTER FETUS SSP JEJUNI EN PATOLOGIA HUMANA
}

\author{
LUZ ECHEVERRI. *
}

Algunos microorganismos, como los Rotavirus y el Campylobacter fetus ssp jejuni, reconocidos y estudiados recientemente, han llegado a ocupar un lugar preponderante en el grupo de enteropatógenos considerados como problema en salud pública.

Las evidencias recientes indican que el Campylobacter fetus ssp jejuni es el causante del $5 \%$ de las gastroenteritis agudas (1). A.R. Kaplan, de Chicago, se refirió al Campylobacter fetus ssp jejuni como a un agente más común que Shigella o protozoos y tan común, como Salmonella.

El microorganismo ha sido estudiado desde comienzos de este siglo por varios investigadores. En 1.913 Mc Faydean y Stockman describieron morfológicamente como vibrio, a un organismo aislado en casos de aborto en el ganado vacuno y ovino. En 1919 Smith y Taylor lo llamaron Vibrio fetus por ser aislado de abortos en bovinos. En 1.931 Jones y otros, aislaron vibrio de ganado vacuno con problemas intestinales y lo llamaron Vibrio jujuni. Doyle en 1944 lo aisló del intestino de cerdos con disentería y lo denominó Vibrio coli (2).

El primer caso de Vibrio fetus como causante de enfermedad en el hombre, fue informado por Vinzent y colaboradores en 1.947 , en una mujer embarazada que presentó septicemia y luego abortó (3). Florent, en 1953, reconoció un vibrio, catalasa negativo, como flora normal genital, denominándolo Vibrio bululus (2). En 1957 Elizabeth King aisló por primera vez los vibrios en heces del hombre y los llamó "Related vibrios", ya que tenían características comunes con el vibrio reportado por Vinzent pero eran antigénicamente diferentes (4).

En 1959 y 1960 Florent estudió y clasificó al Vibrio fetus dentro de dos subespecies: el Vibrio fetus ssp venerealis, causante de aborto y esterilidad en el ganado; de transmisión venérea, $\mathrm{H}_{2} \mathrm{~S}$ negativo y que no crecía en $1 \%$ de glicina ni en $3,5 \%$ de cloruro de sodio y el Vibrio fetus ssp intestinalis, causante de abortos esporádi$\cos$ en el ganado vacuno y ovino, $\mathrm{H}_{2} \mathrm{~S}$ negativo o débilmente positivo, que tampoco presentaba crecimiento en $3,5 \%$ de cloruro de sodio pero sí en $1 \%$ de glicina (2).

En 1.962 Mohanhy y colaboradores clasificaron al Vibrio fetus dentro de 3 grupos: Tipo I: no producía $\mathrm{H}_{2} \mathrm{~S}$ y no crecía en $3.5 \%$ de cloruro de sodio ni en 1\% de glicina. Tipo II: era $\mathrm{H}_{2} \mathrm{~S}$, no crecía en medio salino, pero sí en glicina al $1 \%$. Tipo III: era $\mathrm{H}_{2} \mathrm{~S}$ positivo y no crecía en $3,5 \%$ de cloruro de sodio ni en $1 \%$ de glicina (2).

En 1.961 Bryner y colaboradores dividieron al Vibrio fetus dentro de tres isotipos. Tipo I: era $\mathrm{H}_{2} \mathrm{~S}$ negativo y crecía en $1 \%$ de bilis pero no en glicina al $1 \%$ ni en cloruro de sodio al 3,5\%. Subtipo I: era $\mathrm{H}_{2} \mathrm{~S}$, débilmente positivo crecía en $1 \%$ de bilis pero no en $1 \%$ de glicina ni en $3,5 \%$ de cloruro de sodio. Tipo II: era $\mathrm{H}_{2} \mathrm{~S}$ positivo y crecía en $1 \%$ de bilis y en $1 \%$ de glicina pero no en $3,5 \%$ de cloruro de sodio (2).

\footnotetext{
* Estudiante de Post-Grado, Unidad de Bacteriología General, Grupo de Microbiología e Inmunología. Instituto Nacional de Salud - Bogotá.
} 
En 1963 Sebald y Veron demostraron que existían diferencias fundamentales en la concentración de guanina + citocina $(G+C)$ en el DNA, entre el grupo microaerofílico del $V$. fetus y los vibrios verdaderos como $V$. cholerae y $V$. parahaemolyticus. La proporción G + C del Vibrio bubulus es de $30,1 \pm 0,3$ moles por ciento, la del Vibrio fetus es de $34,3 \pm 0,6$ moles por ciento, en tanto que la del Vibrio verdadero es de $47,2 \pm 0,7$ moles por ciento. Ellos concluyeron que por estas diferencias de $\mathrm{G}+\mathrm{C}$, las especies Vibrio fetus y Vibrio bubulus, no debían pertenecer al gérmen Vibrio proponiendo un nuevo género, Campylobacter (del griego campy curva, bacter bastón), para dichas especies (5). La definición de los Campylobacter, dada por estos autores fue: bacilos gram negativos, en forma de bastón, delgados y curvos, que algunas veces pueden presentarse en forma esférica; móviles por el flagelo polar (monotrico o peritrico). No son proteolíticos, no acidifican los medios con carbohidratos, reducen los nitratos a nitritos, no esporulan y son anaerobios estrictos o facultativos. El valor de sus concentraciones de G + C. está entre $30 \%$ y $34 \%$. Son saprofitos o algunas veces patógenos para el hombre y los animales. La especie tipo de este género es el Campylobacter fetus.

En 1.971 Berg y otros hicieron un estudio serológico del Vibrio fetus tipificándolo antigénicamente y correlacionándolo con el sistema de biotipos de Bryner y otros: Grupo A-1 era el biotipo I, con un antígeno A estable al calor; Grupo A-sub 1, biotipo sub 1 con un antígeno A estable al calor; Grupo $\mathrm{B}$ era el biotipo 2, con un antígeno $\mathrm{B}$ estable al calor; Grupo C, tenía un antígeno C estable al calor y no presentaba biotipo. Estas cepas crecen a $42^{\circ} \mathrm{C}$. y son del serotipo Montana 1 (2).

En 1.973 Veron y Chatelain clasificaron el "Related vibrio" como Campylobacter coli y Campylobacter jejuni (2).

En 1.975 Smibert clasificó en el Manual Bergey al Campylobacter de la siguiente manera: Campylobacter fetus ssp fetus es el mismo Vibrio fetus ssp veneralis de Florent. C. fetus ssp intestinalis igual al Vibrio fetus ssp intestinalis clasificados por Florent. Campylobacter fetus ssp jejuni que comprende los Campylobacter coli y jeuni de Veron y Chatelain y los "Related vibrios" clasificados por King, pues las características de estos organismos son las mismas y no representan a diferentes especies (2).

\section{MORFOLOGIA Y FISIOLOGIA}

El Campylobacter está dividido en dos grupos de acuerdo con la capacidad del organismo de producir catalasa: el Campylobacter sputorum es catalasa negativo; anteriormente era considerado como saprofito pero ahora se sabe que es patógeno. Los del grupo catalasa positivos relacionados con el Campylobacter fetus, son causantes de enfermedades en el hombre y en los animales (6 - 7). Fig. No. 1.

El Campylobacter fetus presenta la forma de bacilo en espiral, de 1,5 a 3,5 micrometros de largo por 0,2 a 0,4 micrometros de ancho. Monotrico; al microscopio de contraste de fases se observa su motilidad rápida, característica. Es oxidasa positivo. Su energía para el crecimiento proviene del ciclo del ácido tricarboxílico. Su pared celular está compuesta por los aminoácidos: alanina, glicina, ácido glutámico, ácido aspártico, cisteína y ácido diamino-pimélico; los carbohidratos que la componen son galactosa y glucosa, o galactosa, glucosa y manosa; los lípidos son fosfatidiletanolamina, fosfatidil-glicerol y fosfatidil-inositol. La composición de amino ácidos del flagelo es similar en todos los serotipos; hacen parte de él todos los amino ácidos excepto la cisteína (2).

El Campylobacter fetus ssp jejuni crece a $37^{\circ} \mathrm{C}$ y $42^{\circ} \mathrm{C}$ pero no a $25^{\circ} \mathrm{C}$; es sensible al ácido nalidíxico (8) y crece en agar con trifeniltetrasolio (7). Estas son las reacciones más útiles para distinguirlo de las otras dos subespecies de Campylobacter fetus, como se observa en el cuadro No. 1 (9).

Algunos investigadores han utilizado para el crecimiento y desarrollo de C. fetus ssp jejuni, atmósferas de una mezcla gaseosa de $15 \%$ de $\mathrm{CO}_{2}$ y $85 \%$ de $\mathrm{N}$ o de $\mathrm{H}$, con lo cual el $\mathrm{O}_{2}$ alcanza una concentración de 5-7\% (7); 
otros, han empleado un ambiente de $5 \%$ de $0_{2}, 10 \%$ de $\mathrm{CO}_{2}$ y $85 \%$ de $\mathrm{H}$ (2) (10). Esta última es la mezcla utilizada actualmente en el Instituto Nacional de Salud, con muy buenos resultados.

La aerotolerancia de la cepa del Campylobacter fetus ssp jejuni puede aumentarse al adicionar al medio Brucella, pequeñas cantidades de compuestos dehidroxifenílicos como la norepinefrina (2) (11-13) o altas concentraciones de sales de hierro (2) (7) (11-13). Este medio con suplemento, permite el aislamiento del Campylobacter en una atmósfera entre 17 y $21 \%$ de $0_{2}$ (2) (7) (13). El Campylobacter fetus posee en su célula, catalasa y su-peróxido dismutasa. Se ha demostrado que en el medio de cultivo caldo Brucella sin inocular, cuando se expone a la luz y al aire, se producen por reducción foto química, radicales de alta energía (2) (13), tales como peróxidos y superóxidos, que inhiben el crecimiento de Campylobacter fetus, en concentraciones tan pequeñas como $0,00124 \%$ de $\mathrm{H}_{2} \mathrm{O}_{2}$ (2). El sulfato ferroso, el bisulfito y el piruvato previenen y/o destruyen dichos radicales del medio (2) (11). La adición de catalasa y superóxido dismutasa al medio de cultivo, aumenta el crecimiento del Campylobacter por reducir la toxicidad de éste (2).

\section{CUADRO № I \\ DIFERENCIACION DE LAS SUBESPECIES DE CAMPYLOBACTER FETUS}

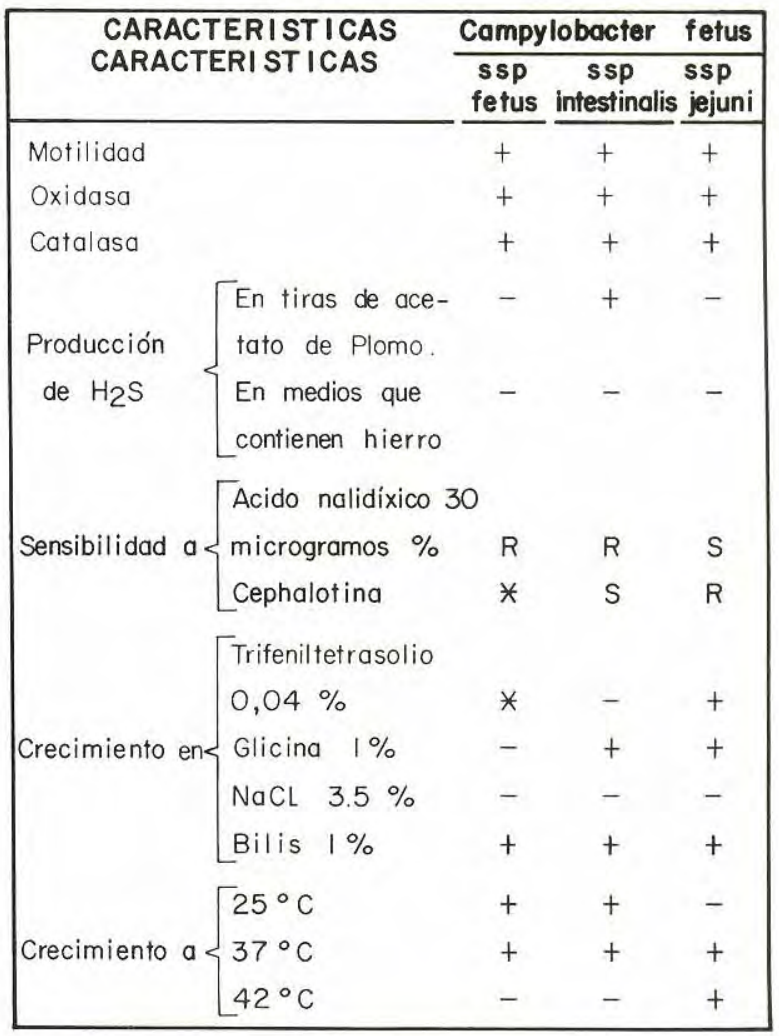

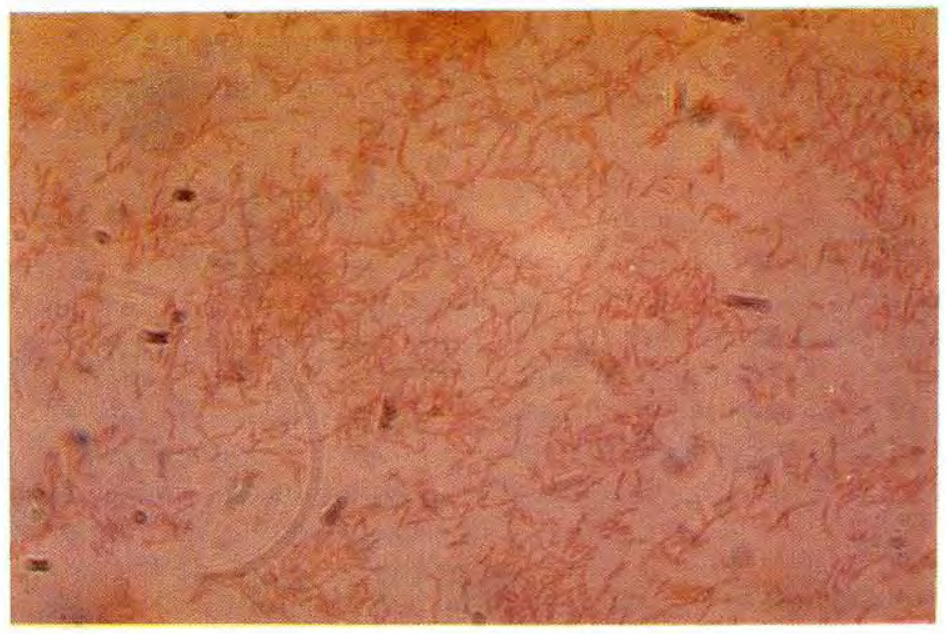

Figura 1. Coloración de Gram para Campylobacter fetus ssp jejuni donde se observa la típica morfología de características curvadas, en forma de $S$, en espiral. 


\section{METODOS DE AISLAMIENTO}

El aislamiento del Campylobacter requiere técnicas especiales como la filtración diferencial o la siembra en un medio que contenga antibióticos selectivos (7).

La filtración fue la primera técnica utilizada, con buenos resultados, por Dekeryer y otros en 1.972 (11); basada en la posibilidad de que el Campylobacter pase a través de un filtro de 0,65 micrometros, tiene como ventaja el no requerir del uso de un medio selectivo, sino simplemente de agar sangre. Este método si bien impide el crecimiento de otros gérmenes, a su vez inhibe el crecimiento del Campylobacter (7) (10).

Los medios de cultivo conocidos hasta la fecha son:

Brucella agar: Con 5 a $7 \%$ de sangre de caballo hemolisada por el calor, más un suplemento, por litro de: vancomicina $10 \mathrm{mg}$, sulfato de polimixina B 2.500 UI y lactato de trimetropina $5 \mathrm{mg}$. Este es el medio recomendado por Skirrow. Algunos variantes del mismo han sido utilizados con muy buenos resultados (7) (14 - 15).

Tioglicolato agar: Con $15 \%$ de sangre de cordero adicionada de bacitracina $25 \mathrm{UI} / \mathrm{ml}$, novobiocina $5 \mathrm{microgramos} / \mathrm{ml}$, ciclohexamida 50 microgramos, colisticina $10 \mathrm{U} / \mathrm{ml}$, cefalotina $15 \mathrm{microgramos} / \mathrm{ml}$. Es un medio recomendado por Butzler (7).

Columbia agar: Es un medio selectivo para el Campylobacter, el cual se le añade el suplemento antimicrobiano del medio de Skirrow (16), con una concentración mayor de sulfato de polimixina $B$. La sangre hemolisada de caballo al 7\% se utiliza con el fin de eliminar los antagonistas de la trimetropina (7) (16).

El Capylobacter crece en tioglicolato o en un medio de extracto de levadura peptona, al cual se le adicione el suplemento antimicorbiano. Al incubar en una atmósfera de $6 \% 0_{2}$ y a una temperatura de $42^{\circ} \mathrm{C}$, por 48 horas, se observan colonias planas, peque- ñas, brillantes, no hemolíticas, mucosas, lisas o rugosas (2) (16).

Como medio de transporte para recuperar Campylobacter jejuni de suspensiones fecales se ha utilizado la solución salina peptonada, incubando a $42^{\circ} \mathrm{C}$ por 6 a 8 horas. La incubación por más tiempo permite el crecimiento de otra flora (17).

Con el mismo fin se ha utilizado caldo tioglicolato con $0,16 \%$ de agar y el suplemento antimicrobiano recomendado por Skirrow, adicionado de anfotericina B, 2 $\mathrm{mg} / \mathrm{l}$, para inhibir el crecimiento de levaduras. La siembra en este medio se refrigera durante toda la noche (17) o por ocho horas (8) (18) y luego se repica en medio selectivo.

\section{Inoculación del Medio}

El Agar Brucella puede ser inoculado directamente con la muestra de heces o con la muestra rectal tomada con escobillón, o indirectamente después de haber refrigerado la muestra con el medio de transporte. (9).

Inoculación Directa de las Muestras:

De la muestra rectal o de la muestra diarreica se inoculan de 3 a 5 gotas en el agar; de las muestras sólidas se prepara una suspensión en solución salina, se mezcla en un vortex y se inoculan también de 3 a 5 gotas en el agar. En todo caso se siembra por agotamiento para obtener un mejor aislamiento del gérmen. (9).

Inoculación Indirecta de las Muestras:

El escobillón con la muestra rectal se introduce hasta $1 \mathrm{~cm}$. por debajo del nivel del tioglicolato, se agita (con el fin de inocular el microorganismo dentro de un área de baja tensión de oxígeno) y puede sacarse o dejarse dentro del tubo. De las muestras diarreicas, se inoculan 5 gotas en el tioglicolato; de las muestras sólidas, se prepara una suspensión en solución salina y se pasan 5 gotas al tioglicolato.

Todos los tioglicolatos se dejan en refrigeración durante ocho horas, antes de repicarlos. Para el repique se toma la 
muestra con una pipeta Pasteur, aproximadamente $2 \mathrm{~cm}$. por debajo de la superficie del medio, se lleva al agar, se siembra por agotamiento y se incuba (9).

\section{Incubación:}

Para el aislamiento del Campylobacter fetus ssp jejuni las cajas sembradas se incuban a $42^{\circ} \mathrm{C}$ a $37^{\circ} \mathrm{C}$ y a $25^{\circ} \mathrm{C}$ por 48 horas, en una atmósfera de 5\% de oxígeno, $10 \%$ de bióxido de carbono y 85\% de nitrógeno (8-9) (18).

\section{Identificación:}

Su crecimiento a $42^{\circ} \mathrm{C}$ y $37^{\circ} \mathrm{C}$ pero no a $25^{\circ} \mathrm{C}$, la sensibilidad al ácido nalidíxico en una concentración de 30 microgramos \% (8-9) y su crecimiento en un medio que contenga cloruro de trifeniltetrasolio, son las pruebas más importantes de identificación del Campylobacter fetus ssp jejuni. (7) (9).

\section{EPIDEMIOLOGIA}

El Campylobacter fetus ssp jejuni ha sido reconocido como causante de enfermedades, principalmente entéricas, en el hombre. En estudios adelantados en Europa, Africa, Norte América y Australia se le ha reconocido como agente patógeno en 3 a $11 \%$ de los pacientes con diarrea (18). En el Reino Unido se considera que del 4,2 al $13,9 \%$ de los casos de diarrea infecciosa, se deben a Campylobacter (16). Los primeros informes sugirieron que el $V$. fetus era un oportunista de los huéspedes debilitados, pero ahora se conoce que los individuos sanos son los huéspedes más susceptibles de infectarse con Campylobacter fetus ssp jejuni (18).

En una investigación realizada por Skirrow en 803 heces de pacientes con diarrea, 57 $(5.1 \%)$ fueron positivas para Campylobacter; las heces de 194 personas sin diarrea presentaron cultivo negativo. En el suero de $31 / 38$ personas con enteritis por Campylobacter fueron encontradas aglutininas específicas, con aumento del título en 10 de las 31 personas estudiadas (15).

En Suecia se comunicó C. jejuni en 15 sujetos (13 pacientes con diarrea y 2 portadores sanos); 8 de los 13 pacientes con diarrea habían sido infectados en el extranjero (Finlandia, España, Gran Bretaña, Tanzania) (19), lo que sugiere una contaminación por los alimentos.

En denver, Colorado, el C. fetus je junifue aislado de $39(4,1 \%)$ de 956 muestras de heces de pacientes con diarrea. De 44 personas que tuvieron contacto con los 39 casos anteriores, 12 presentaron síntomas diarreicos, en 8 de las cuales los cultivos de heces fueron positivos para el $C$ fetus ssp jejuni; sólo 1 de los 32 individuos asintomáticos fue positivo (18).

En Edimburgo fueron examinadas 196 muestras de pacientes con diarrea, 17 $(8,7 \%)$ de las cuales fueron positivas para campylobacter; el $47 \%$ de estos pacientes eran menores de 10 años, 7 niños y 1 niña. 50 individuos asintomáticos fueron negativos (20).

En Kigali (Rwanda), de 204 niños con diarrea, $22(11 \%)$ presentaron Campylobacter, 2 de ellos asociados con Salmonella. No se aisló Campylobacter en 58 niños asintomáticos. La frecuencia de Campylobacter fue más alta en niños entre 12 y 24 meses de edad, probablemente debido al suelo contaminado (21).

En Arizona se informaron 41 cultivos positivos para C. jejuni, de heces diarreicas de 800 niños y 4 de 100 adultos. Solo 13 de 1.000 niños hospitalizados, sin diarrea, fueron positivos. No se pudo aislar Campylobacter de 548 heces de: adultos asintomáticos, niños u homosexuales; tampoco se aisló de la flora vaginal de mujeres jóvenes sanas embarazadas ni de mujeres con vaginitis inespecíficas, lo que sugiere que el agente no hace parte de la flora normal y que la transmisión por medio de la flora vaginal no es la forma común de infección al feto. (18).

Algunas investigaciones realizadas en el Africa han demostrado portadores asintomáticos de Campylobacter en un $16 \%$ de niños, hecho que no se ha registrado en Norte América. Las características dietéticas, socioeconómicas y culturales de estos 
dos pueblos son divergentes y por ello quizas esta diferencia tan marcada (18).

En Manchester se examinaron 338 muestras fecales: 182 pertenecían a pacientes con diarrea esporádica, $14(7.6 \%)$ de las cuales fueron positivos para Campylobacter; 60 a personas seleccionadas antes de trabajar en la industria alimenticia, $1(0,2 \%)$ de las cuales fue positiva para Campylobacter; 31 a pacientes convalecientes, portadores de microorganismos patógenos, de los cuales no se aisló Campylobacter. Dos terceras partes de los aislamientos fueron de personas entre 15 y 44 años de edad; la distribución por sexos fue aproximadamente igual (22).

En Bélgica, de 22.000 muestras examinadas desde 1.970 , ha sido aislado el C. jejunien el $5,9 \%$ de las muestras diarreicas y en el 1,3\% de las muestras normales. El aislamiento varió con las estaciones, con aumento al 8,9\% en el verano. El número de cultivos positivos puede aumentar por el contacto con personas con Campylobacter; ésto se ha observado en 5 guarderías de Bruselas, donde, del 20 al 50\% de los niños se infectaron y tuvieron diarrea (23).

En el año de 1.977 el Centro de Vigilancia y Control de Enfermedades en Inglaterra y Escocia, recopiló 1.513 aislamientos de C. jejuni. La mayoría de los pacientes (1.265) tuvieron diarrea acompañada de sangre, pus o moco en 186 casos; con vómito en 187 y con dolor abdominal fuerte en 167. La edad de los pacientes fluctuó entre un día y 100 años: hubo neonatos, todos hijos de madres infectadas y dos mujeres de 71 a 80 años, las cuales murieron. Se presentó septicemia en cuatro pacientes de 4, 18, 46 y 68 años (24).

En un niño de 6 días se aisló Campylobacter, adquirido de su madre, quien presentaba enteritis (25).

La enfermedad entérica se manifiesta por diarrea, que comienza gradualmente en algunos pacientes y en forma explosiva en otros; frecuentemente es de color bilis, acuosa y por lo general presenta sangre, pus y moco. El estado de diarrea profusa dura de uno a tres días. Algunos de los síntomas que la acompañan son: dolor abdominal fuerte, fiebre, vómito, mialgias, altragias, dolor de cabeza (14); para algunos pacientes el dolor abdominal es más molesto que la diarrea.

Los niños tienden a recuperarse más fácilmente que los adultos; la enfermedad puede durar de pocos días a tres semanas. El período de incubación fluctúa entre 2 y 11 días.

Se ha observado que la alimentación prematura con sólidos precipita la reaparición de los síntomas (15).

El yeyuno y el íleon son los órganos donde se producen más comúnmente las lesiones intestinales. La necropsia realizada en dos casos reveló una yeyunitis hemorrágica (25).

En las biopsias rectales practicadas a pacientes con infección por C. fetus ssp jejuni se han encontrado áreas con una marcada infiltración inflamatoria, con frecuente pérdida del epitelio superficial, congestión capilar, edema y presencia de polimorfo-nucleares. Son casos que histológicamente sugieren el diagnóstico de colitis ulcerativa (14) (16) (26).

En sangre periférica se observa leucocitosis con predominio de polimorfo-nucleares; la velocidad de sedimentación está aumentada (8).

El tratamiento se hace con tetraciclina; eritromicina e hidratación.

Al Campylobacter fetus ssp jejuni, además de su relación con los cuadros clínicos de enteritis, se le ha encontrado como agente único o asociado en casos de colecistitis, meningitis y septicemias y como agente concomitante en casos de enfermedades crónicas.

En Bruselas se comunicaron en 5 años 7 casos de septicemia, en 5 de los cuales se aisló el mismo Campylobacter, de la sangre y de las heces (20).

Un paciente de 67 años de edad, con enfermedad de Waldenstrom, presentó fiebre y escalofrío durante una de las transfusiones sanguíneas que se le hicieron. 
El cultivo de sangre, en ese momento, fue positivo para C. jejuni después de 36 horas de incubación; en 3 nuevos cultivos de sangre se aisló también el germen. Uno de los donantes presentó un título de anticuerpos de 1:640 contra la cepa aislada del paciente, lo cual hace suponer que aquel fue la fuente de infección. (27). En Liverpool se comunicaron 2 casos de meningitis, asociados con el C. jejuni; un hombre de 29 años y un niño de 7 , ambos con cultivo de LCR negativo, pero con cultivo de heces positivo para C. jejuni; un hermano del niño y el perro de su casa, también tuvieron cultivos de heces positivos. Evidencias circunstanciales en estos casos sugirieron una posible asociación entre la meningitis y el C. jejuni (28).

En Inglaterra se comunicaron tres casos de colecistitis asociados con Campylobacter: en un niño de 11 años y en dos mujeres de 32 y de 60 años, en los cuales se aisló $C$. jejuni de la bilis (29). En Bélgica se informó sobre el caso de un paciente de 32 años que presentó C. jejunien bilis y heces; al mes tuvo un título de 1:1248 de aglutininas específicas contra antígenos homólogos (38).

En el centro de cancerología de Houston se publicó el primer caso de infección por Campylobacter en un paciente de 25 años con linfoma de Hodgkin, el cual había tenido contacto previo con animales (31).

\section{TRANSMISION}

El Campylobacter, se ha aislado hasta en un $16 \%$ de individuos asintomáticos. En la adquisición de la infección juegan un papel importante las condiciones dietéticas, socioeconómicas y culturales (18).

El hombre adquiere Campylobacter por la ingestión de leches sin pasteurizar, agua, alimentos contaminados y por contacto con animales domésticos y aves de corral (16). En el área de Southompton, 7 de 34 muestras de agua de mar y 37 de 50 muestras de aguas frescas fueron positivas para Campylobacter jejuniy Eschericha coli; estos datos sugieren que el Campylobacter en el agua está relacionado con la contaminación por materias fecales de mamíferos, aves y humanas (32).
Un informe de los Estados Unidos indicó que un brote de gastroenteritis, en aproximadamente 200 personas, se debió al consumo de agua de acueducto; el Campylobacter se aisló a partir de 5 de 9 muestras rectales (4). Teóricamente la contaminación con los alimentos no debería suceder, ya que los correctos cuidados de preparación evitarían la propagación del microorganismo; sin embargo, el descuido en las medidas higiénicas permite su propagación. Amas de casa, carniceros y trabajadores de plantas procesadoras de pollos se han contaminado en esta forma (7).

King sugirió que los pollos podrían ser la fuente primaria de infección para el hombre, basada en la importancia que le dio el hecho de que ha este tipo de organismos se le atribuía la hepatitis vibriónica en aves de corral (15). Las investigaciones realizadas en 63 pollos muertos, revelaron que $39(62 \%)$ eran positivos para Campylobacter jejuni y que de 167 aves de corral aparentemente sanas, $114(68 \%)$ dieron cultivos positivos para el mismo germen (33). Otros estudios hechos en una planta procesadora de pollos demostraron que (31) (91\%) de 34 pollos eran portadores (43).

En el estudio de un brote de 29 casos de gastroenteritis, ocurrido luego de la ingestión de pollos en una recepción matrimonial. Se aisló Campylobacter de las heces en uno de los casos. Al mes se hicieron aglutinaciones serológicas a ésta y a tres pacientes más, encontrándose en ellos títulos de $1 / 320$ y $1 / 640$, lo cual sugirió que estos casos se infectaron con el mismo microorganismo.

Se hicieron cultivos con muestras tomadas de un pollo de la misma productora de los consumidos en la recepción, aislándose Campylobacter; sin embargo, no fueron detectadas aglutininas contra este organismo en el suero de los pacientes; los sueros fueron probados también contra cuatro cepas aisladas de pollos, para dos de las cuales presentaron títulos tan altos como los hallados con la cepa humana; con los otros no se demostró reacción cruzada (35). 


\section{LUZ ECHEVERRI}

El Campylobacter jejuni ha sido aislado de animales domésticos como el perro y el gato (14). En estudios realizados en Rio de Janeiro, en 25 perros normales no se aisló Campylobacter jejuni, pero sí en $5(5.5 \%)$ de 90 perros con diarrea. En Suecia fue comunicadó el aislamiento del germen en 2 miembros de una familia y en el perro de la casa, el cual presentaba enteritis (36).

En Suiza se informó el caso de una enfermera que presentó enteritis, lo mismo que el gato de su casa; de ambos se aisló C. jejuni cuyas cepas tuvieron antibiogramas idénticos. En la finca de donde provino el animal se tomaron muestras de heces a otros ocho gatos; tres de ellos, recién nacidos, fueron positivos para C. jejuni (37).

En el cuadro No. 2 muestra los datos obtenidos en una investigación realizada en Denver, Colorado, sobre C. jejuni en animales domésticos (18).

CUADRO № 2

AISLAMIENTO DE CAMPYLOBACTER FETUS SUBESPECIE JEJUNI EN ANIMALES DOMESTICOS (18)

\begin{tabular}{|l|c|c|c|}
\hline \multicolumn{1}{|c|}{ GRUPOS DE ANIMALES } & $\begin{array}{c}\text { CASOS } \\
\text { POSIT I VOS }\end{array}$ & $\begin{array}{c}\text { CASOS } \\
\text { INVESTI- } \\
\text { GADOS }\end{array}$ & $(\%)$ \\
\hline$\underline{\text { Animales Caseros : }}$ & $\underline{5}$ & $\underline{60}$ & $\underline{(8,3)}$ \\
Cachorros & 5 & 9 & $(55,5)$ \\
Perros & 0 & 38 & $(0)$ \\
Gatos & 0 & 13 & $(0)$ \\
Perros de Perrera $:$ & $\underline{74}$ & $\underline{271}$ & $\underline{(27,3)}$ \\
Cachorros & 67 & 192 & $(34,9)$ \\
Perros Adultos & 7 & 79 & $(8,9)$ \\
Criaderos de Gatos & $\underline{4}$ & $\underline{112}$ & $\underline{(3,6)}$ \\
Gatos recién nacidos & 4 & 67 & $(0,6)$ \\
Gatos & 0 & 45 & $(0)$ \\
\hline
\end{tabular}

\section{BIBLIOGRAFIA}

1. Golden W, Fellow MF. Campylobacter fetus major enteritic pathogen, Jama. 1979; 242: 2519.

2. Smibert RM. The genus Campylobacter. Ant Rev. Microbil. $1978 ; 32: 673$.

3. Torphy De,Bond WW. Campylobacter fefus infections in children. Pediatrics. 1979; 64: 898.
4. Campylobacter enteritis (Leading article) Lancet. 1978; 2: 135 .

5. Sebald $M$, Veron $M$. Teneur en bases de L'ADN et classification des vibrions. Ann. Inst. Pasteur. 1963; 105: 897 .

6. Loesche WJ, et al. Biochemical characteristics of Vibrio sputorum and relationship to $V$ ibrio bubulus and Vibrio fetus. J. Bacterial, 1979; 8: 737 .

7. Butzler JP, Skirrow MB. Campylobacter enteritis, Clinics in gastroenterolegy. 1979; 8: 737 .

8. Blaser MJ, et al. Campylobacter enteritis: Clinical and epidemiologic features. Ann. Intern. Med. 1979; 91: 179.

9. Kaplan RL. Campylobacter. Manual of Clinical Microbiology. $1980 ; 235$.

10. Skirrow MB. Campylobacter and enteritis. Published as a service to microbiology by Oxoide Limited. 1979; 1.

11. Hoffman PS, etal. Estudies of the microaerophilic nature of Campylobacter fetus subsp. iejuni. II Role of exogenous superoxide anions and hidrogen peroxide. Can J. Microbiol $1979 ; 25: 8$

12. BowdreJH, et al. Stimulatoroy effect of dihydroxyphenil compounds on the aerotolerance of Spirillum voluntans and Campylobacter fetus subspecies jejuni. Applied and Environmental Microbiology. 1976; $31: 127$.

13. Niekus HGD, et al. The effect of different dissolved oxygen tensions on growth and enzime activities of Campylobacter sputorum subspecies bubulus. J. Gen. Microbiol. 1977; 103: 215 .

14. Lambert ME, et al. Campylobacter colitis. Br. Med. J. $1979 ; 1: 857$.

15. Skirrow MB. Campylobacter enteritis: A "new" disease. Br. Med. J. 1977; 2: 9 .

16. Willoughby CP, et al. Campylobacter colitis. J. Clin. Pathol. $1979 ; 32$ : 986 .

17. Wang $W L$, et al. Isolation of Campylobacter. Br. Med. J. $1978 ; 2: 57$.

18. Blaser $M J$, etal. Reservoirs of humancampylobacteriosis. Journal of infectious diseases. 1980; 141:665.

19. Lindquist B, etal. Campylobacter enteritis in Sweden. Br. Med. J. $1978 ; 1: 303$.

20. Brunton WAT, Heggie D. Campylobacter associated diarrhoea in Edinburgh. Br. Med. J. 1977; 2: 956.

21. De mol P, Bosmans E. Campylobacter enteritis in Central Africa. Lancet. 1978; 1: 604 .

22. Dale B. Campylobacter enteritis. Br. Med. J. 1977; 2: 318 .

23. Lauwers $\mathrm{S}$. et al. Campylobacter enteritis in Brussels. Lancet. $1978 ; 1: 604$. 


\section{CAMPYLOBACTER FETUS SSP JEJUNI EN PATOLOGIA HUMANA}

24. Comunicable disease surveillance centre (Public health la boratory service) and the comunicable diseases (Scotland) Campylobacter infections in Britain 1977; Br. Med. J. $1978 ; 1: 1357$.

25. Mawer SL, Smith BAM. Campylobacter infection of premature baby. Lancet. 1979; 1: 1041.

26. Price $A B$, et al. Acute diarrhea: Campylobacter colitis and the role of rectal biopsy, J, Clin. Pathol, 1979; 32: 990.

27. Pepersack $F$, et al. Campylobacter jejuni post transfusional septicaemia, Lancet, 1979; $2: 911$.

28. Wright E P Meningism associated with Campylobacter jejuni enteritis. Lancet, 1979; 1: 1092

29. Darling WM, et al. Campylobacter cholecystitis. Lancet. 1979; 1: 1302

30. Mertens A, De smet $M$. Campylobacter cholecystitis Lancet. 1979; 1: 1093.
31. Krutchik An, Velásquez W. Campylobacter fetus infection in a patient with Hodkin's disease. Jama. 1977; 238: 1810.

32. Knill M. et al. Envirormental isolation of heat tolerant Campylobacter in the Sonuthamton area. Lancet. 1978 2: 1002.

33. Bruce D, et al. Campylobacter enteritis. Br. Med. J. $1977 ; 2: 1219$

34. Riveiro CD. Campylobacter enteritis. Lancet. 1978: 2: 270 .

35. Hayek LJ. Cruickshank JG. Campylobacter enteritis. Br. Med. J. 1977; 2: 1219

36. Ferreira MCS, etal, Campylobacter, dogs and human enteritis. Vet. Rec. 1979; 105: 451

37. Svedhem A, Norkzans G. Campylobacter iejuni enteritis transmitted from cat to man. Lancet. 1980; $1: 713$. 